\title{
PELAKSANAAN KHIYAR SYARAT DALAM JUAL BELI DI \\ PASAR SANGKUMPAL BONANG PADANGSIDIMPUAN DI TINJAU DARI KOMPILASI HUKUM EKONOMI SYARIAH
}

\author{
SOFIA SARI
}

IAIN Padangsidimpuan

\begin{abstract}
This papers discussed about the implementation of the khiyar syarat, and review of Islamic law in implementing the khiyar syarat. Then problems often occur in buying and selling activities, the clothes merchants do not want to return the buyer's money because there is no agreement between the seller and the buyer. This study aims to determine how the khiyar syarat are implemented in the sale at the Sagumpal Bonang Market in Padangsidimpuan. And to find out about the review of the Kompilasi Hukum Ekonomi Syariah (KHES), on the implementation of the Khiyar syarat in buying and selling at Sangkumpal Bonang Market in Padangsidimpuan. This research is field research using a sociological juridical approach. Sources of data are primary data and secondary data. The data were collected by instruments such interviews, observation and documentation. Moreover, the process of data analysis was classified into descriptive research, namely to find specific and realistic about the problem that is happening and express themselves in the form of symptoms in order to solve existing problems in implementing khiyar syarat. The practice of the khiyar syarat carried out by some clothing traders in the Sangkumpal Bonang Market in Padangsidimpuan namely if the goods do not match after the sale and purchase transaction, the buyer can return the item but is exchanged for other goods, but if there are no similar items the buyer redeem the goods but the item is in good condition. In Reviewing Islamic Law on the terms of conditions in the Sangkumpal Bonang Market in the vicinity of the meeting, it was not in accordance with the requirements, because non-resident clothing traders canceled buying and selling transactions and asked for refunds when found items that did not match the goods were known after buying and selling transactions.
\end{abstract}

Keywords: Khiyar, Buying and Selling, Ekonomi Syariah

Abstrak
Tulisan ini membahas tentang pelaksanaan khiyar Syarat, dan tinjaun
hukum Islam dalam pelaksanaan khiyar Syarat. Maka muncul
permasalahan sering terjadi dalam kegiatan jual beli para pedagang


pakaian tidak mau mengembalikan uang pembeli karena tidak adanya perjanjian antara penjual dengan pembeli. Penelitian ini bertujuan Untuk mengetahui bagaimana pelaksanaan Khiyar Syarat dalam jualbeli di Pasar Sagumpal Bonang Padangsidimpuan. Dan untuk mengetahui tinjaun Kompilasi Hukum Ekonomi Syariah (KHES), terhadap pelaksanaan khiyar Syarat dalam jual beli di Pasar Sangkumpal Bonang Padangsidimpuan. Penelitian ini adalah penelitian lapangan (field research) menggunakan metode pendekatan yuridis sosiologis. Sumber data dalam penelitian ini adalah data primer, data skunder. Instrumen pengumpulan data yang digunakan adalah wawancara, observasi dan dokumentasi.Dan jika ditinjau dari proses analisis datanya maka dapat digolongkan kepada research deskriftif yaitu untuk menemukan secara spesifik dan realistis tentang masalah yang sedang terjadi dan mengekspresikan diri dalam bentuk gejala dengan tujuan untuk memecahkan masalah yang ada dalam pelaksanaan khiyar Syarat. Praktek pelaksanaan khiyar syarat yang dilakukan sebahagian pedagang pakaian di Pasar Sangkumpal Bonang di Padangsidimpuan yaitu apabila barang tidak sesuai setelah terjadinya sebelum transaksi jual beli maka pembeli bisa mengembalikan barang itu tetapi ditukar dengan barang lain, namun apabila tidak ada barang yang sama maka pembeli menukarkan barang yang lain tetapi barang tersebut dalam keadaan bagus. Dalam Tinjauan Hukum Islam terhadap khiyar syarat di Pasar Sangkumpal Bonang di padangsidimpuan belum sesuai dengan khiyar syarat, karena pedagang pakaian tidak boeh membatalkan transaksi jual beli dan meminta kembali uang saat ditemukan barangnya yang tidak sesuai pada barang diketahui setelah terjadi transaksi jual beli.

Kata Kunci: Khiyar, Jual Beli, Ekonomi Syariah

\section{PENDAHULUAN}

\section{Latar Belakang Masalah}

Khiyar adalah bentuk masdhar yang berasal dari kata dasar iktiyar yang berarti memilih, terbebas dari 'aib, melaksanakan pemilihan, Adapun definisinya adalah hak orang yang melalukan transaksi untuk membatalkan transaksi atau meneruskan karena ada alasan syar'i yang membolehkan atau karena kesepakatan dalam transaksi. Khiyar menurut pasal 20 ayat 8 Kompilasi Hukum Ekonomi Syariah yaitu hak pilih bagi penjual dan pembeli untuk melanjutkan atau membatalkan akad jual beli yang dilakukan.

Dalam masalah batas waktu pemberian khiyar pun berbeda-beda. Ada yang memberikan batas waktu satu hari, ada yang memberi batas dua hari, bah 
kan ada yang memberi batas waktu sampai tiga hari. Khiyar mencari dua pilihan yang terbaik antara imda( melanjutkan transaksi) atau ilga ( membatalkan transaksi). Hak khiyar ditetapkan syariat Islam bagi orang-orang yang melakukan transaksi agar tidak dirugikan dalam transaksi yang mereka lakukan. dan juga agar tidak terjadi perselisihan antara penjual dan pembeli, sehingga kemaslahatan yang dituju dalam suatu transaksi tercapai dengan sebaik-baiknya dan tidak ada yang tertipu.

Sedangkan perkembangan dimasyarakat sekarang ini telah mengalami perubahan. Sehingga perubahan ini dapat menyebabkan terutama dalam masalah jual beli di pasar sangkumpal bonang di padangsidimpuan, salah satunya adalah masalah khiyar. Impelementasi khiyar syarat dalam pasar sangkumpal bonang dipadangsidimpuan.Misalkannya Khiyar Syarat sebagaimana di jelaskan dalam pasal

Kompilasi Hukum Ekonomi Syariah pada pasal 271 ayat 1 dan 2 menyatakan bahwa khiyar Syarat adalah : 1). Penjual dan pembeli dapat bersepakat untuk mempertimbangkan secara matang dalam rangka melanjutkan atau membatalkan akad jual beli yang dilakukannya. 2) Waktu yang diperlukan dalam ayat satu(1) adalah tiga hari, kecuali disepakati lain dalam akad.

Peneliti memilih pasar sangkumpal bonang sebagai objek penelitian dalam tulisan ini dengan alasan bahwa Pasar sangkumpal bonang adalah salah satu ikon pasar tradisional padangsidimpuan yang menyediakan berbagai macam barang dengan harga miring baik itu barang bekas maupun barang baru. adapun perbedaan Pasar sangkumpal bonang dengan Pasar tradisional lainnya adalah dari segi objek barang yang diperjual beli. Dipasar sangkumpal bonang barang yang diperjual belikan bukan hanya barang baru seperti terdapat pada pasar-pasar tradisional lainnya. karena barang yang dijual dipasar sagumpal bukan barang baru saja melainkan ada barang bekas juga, maka sangat diperlukan sekali adanya proses khiyar dalam setiap jual beli.

Seperti yang telah di teliti oleh peneliti di pasar sangkumpal bonang tentang masalah khiyar syarat dalam jual beli pakaian. Di pasar sagumpal bonang ada yang memakai khiyar syarat ada juga yang tidak memakai khiyar syarat dalam jual beli. Adapun hasil wawancara yang dilakukan oleh peneliti di toko pakaian tersebut adalah dimana toko tersebut memakai khiyar syarat dalam jual beli pakaian dengan beberapa syarat, diantaranya adalah: 1). jangka waktu maksimal dua atau tiga hari setelah transaksi berlangsung, 2). Barang yang dibeli 
220 | TAZKIR: Jurnal Penelitian Ilmu-ilmu Sosial dan Keislaman

Vol. 03 No. 2 Desember 2017

tidak dalam keadaan rusak, 3). Masih ada merk pakaiannya. 4) pihak-pihak pembeli tidak bisa meminta uang nya kembali.

Oleh karena itu, peneliti juga bermaksud mencari tahu mengapa praktik khiyar yang dilapangan, pihak pembeli tidak boleh meminta uangnya kembali. Berbeda dengan khiayar syarat yaitu pembeli punya hak untuk meneruskan atau membatal kan jual beli selama masih dalam tenggang waktu yang ditentukan Maka peneliti tertarik untuk mengangkat judul "Impelementasi khiyar syarat dalam jual beli dipasar sangkumpal bonang di padang sidimpuan".

\section{RUMUSAN MASALAH}

Rumusan masalah dalam penelitian ini adalah "Bagaimana Pelaksanaan khiyar syarat dalam jual beli di Pasar Sagumpal Bonang?" dan "Bagaimana tinjauan Kompilasi Hukum Ekonomi Syariah (KHES) terhadap pelaksanaan khiyar syarat dalam jual beli di Pasar Sagumpal Bonang?"

\section{TUJUAN PENELITIAN}

Berdasarkan rumusan masalah yang dikemukakan di atas, maka tujuan yang ingin dicapai dari penelitian ini adalah untuk mengetahui Pelaksanaan Khiyar Syarat dalam Jual Beli di Pasar Sangkumpal Bonang Padangsidimpuan di Tinjau Dari Kompilasi Hukum Ekonomi Syariah. Adapun secara rinci, tujuan yang ingin dicapai dari penelitian ini yaitu :

1. Untuk mengetahui bagaimana pelaksanaan khiyar Syarat dalam jual beli di Pasar Sagumpal Bonang Padangsidimpuan.

2. Untuk mengetahui tinjaun Kompilasi Hukum Ekonomi Syariah (KHES), terhadap pelaksanaan khiyar Syarat dalam jual beli di Pasar Sangkumpal Bonang Padangsidimpuan.

\section{KEGUNAAN PENLITIAN}

1. Kegunaan Ilmiah

a. Untuk memperkaya Khazanah keilmuan, terutama bagi penulis sebagai calon Sarjana Hukum.

b. Sebagai bahan pertimbangan dan penelitian Lanjutan mengenai pelaksanaan khiyar syarat.

2. Kegunaan praktis 
a. Sebagai bahan masukan untuk masyrakat khususnya bagi umat Islam yang telah dan akan melakukan transaksi jual beli dan adanya khiyar.

b. Sebagai baham pemikiran yang mendalam untuk memperluas wawasan dibidang pelaksanaan khiyar khususnya bagi peneliti sebagai calon Sarjana Hukum.

3. Prasarat mendapat gelar Sarjana Hukum di Institut Agama Islam Negeri Padangsidimpuan.

4. Bagi penjual di Pasar Sangkumpal Bonang, penelitian ini dapat digunakan sebagai bahan pertimbangan dalam transaksi jual beli dengan adanya hak khiyar.

\section{METODE PENELITIAN}

Penelitian ini menggunakan penelitian lapangan (field research), penelitian ini yang dilakukan langsung dilapangan untuk memproleh imformasi dan data sedekat mungkin dengan dunia nyata, sehingga pengguna hasil penelitian dapat memformulasikan atau memanfaatkan hasil dengan sebaik mungkin dan memproleh data atau imformasi yang selalu terkini. Dalam penelitian ini, data maupaun informasinya, bersumber dari para pedagang dipasar sagumpal bonang di padangsidimpuan. Sumber data adalah subjek dari mana data diperoleh. Data yang dibutuhkan dalm penelitian terdiri dari dua macam sumber, yaitu data primer dan data sekunder. Teknik pengumpulan data yang dilakukan peneliti dalam penelitian ini sebagai berikut. Observasi, Wawancara, Kepustakaan, Dokumentasi

\section{HASIL PENELITIAN}

Berdasarkan analisis data deskriptif, praktek pelaksanaa khiyar syarat yang dilakukan sebahagian pedagang pakaian di Pasar Sangkumpal Bonang di Padangsidimpuan yaitu apabila barang yang tidak sesuai setelah terjadinya transaksi jual beli maka pembeli bisa mengembalikan barang itu tetapi ditukar dengan barang lain, namun apabila tidak ada barang yang pertama maka pembeli menukarkan barang yang lain tetapi barang tersebut dalam keadaan bagus. Akan tetapi sebagian pembeli meminta uangnya kembali karena merasa tidak sesuai barang yang diinginkannya tetapi penjual tidak membolehkannya, karena biasanya mereka hanya menerapkan penukaran barang dengan barang yang sejenis atau seharga saja. Pembeli merasa dirugikan dengan berlangsung 
222 | TAZKIR: Jurnal Penelitian Ilmu-ilmu Sosial dan Keislaman

Vol. 03 No. 2 Desember 2017

transaksi, karena pembeli harus menerima barang yang tidak sesuai dengan keinginan.

Tinjauan Hukum Islam terhadap khiyar syarat di Pasar Sangkumpal Bonang di Padangsidimpuan belum sesuai dengan ketentuan mereka tidak membolehkan untuk membatalkan transaksi jual beli dan meminta kembali uangnya saat ditemukan barangnya yang tidak sesuai pada barang diketahui setelah terjadinya transaksi jual beli, barang yang tidak sesuai tersebut bukan karena kelalaian pembeli.

\section{KESIMPULAN}

Dari penelitian dan pembahasan yang dilaksanakan dapat di ambil kesimpulan sebagai berikut:

Praktek pelaksanaan khiyar syarat yang dilakukan sebahagian pedagang pakaian di Pasar Sangkumpal Bonang di Padangsidimpuan yaitu apabila barang yang tidak sesuai setelah terjadinya sebelum transaksi jual beli maka pembeli bisa mengembalikan barang itu tetapi ditukar dengan barang lain, namun apabila tidak ada barang yang pertama maka pembeli menukarkan barang yang yang lain tetapi barang tersebut dalam keadaan bagus. Akan tetapi sebagian pembeli meminta uangnya kembali karna merasa tidak sesuai barang yang diinginkannya tetapi penjual tidak membolehkannya, karena biasanya mereka hanya menerapkan penukaran barang dengan barang yang sejenis atau seharga saja. Pembeli merasa dirugikan dengan berlangsung transaksi, karena sipembeli harus menerima barang yang tidak sesuai dengan keinginan.

Tinjauan Hukum Islam terhadap khiyar syarat di Pasar Sangkumpal Bonang di Padangsidimpuan tidak ditemukan bentuk khiyar syarat, pada pedagang pakaian, karena mereka tidak membolehkan untuk membatalkan transaksi jual beli dan meminta kembali uangnya saat ditemukan barangnya yang tidak sesuai pada barang diketahui setelah terjadinya transaksi jual beli, barang yang tidak sesuai barang bukan merupakan kelalaian pembeli. 


\section{DAFTAR PUSTAKA}

Abdurrahman, figh Muamalah Jakarta: Kencana, 2010.

Amir Syrarifuddin, figh muamalah, Jakarta: Prasada Media, 2005.

Abdul Rahman Ghazaly, Ghufroapin Ihsan, dan Sapiuddin, fiqih Muamalat, Jakarta: Preneda Media Group, 2010.

Al Imam Abu Abdullah Muhammad Ismail Al Bukhari, Shahih Bukhari Jilid III, Semarang: CV.Asy Syifa, 1992.

Burhan Bugin, Analisis Data Penelitian Kualitatif, Jakarta: PT Raja Grapindo Persada, 2008.

Dedy Mulyana, Metode Penelitian Kualitatif, Bandung: PT Remaja Doskaraja, 2002.

Gufron A. Masabi, Fiqh Muamalah Kontekstual, Jakarta: PT. Raja Grafindo Persada, 2002. Gemala Dewi, dkk. Hukum Perikatan Islam di Indonesia, Jakarta: Kencana, 20005.

H. Ahmad Wardis Muslich, Fikih Muamalah, Ed 1, Cet 2 Jakarta: Amzah, 2017.

Iman Zainuddin Ahmad Ibnu Abdul, Mukhtasor Shahih Bukhori Juz I Bairut: Libanon, 1994.

Hendi Suhendi, fiqih muamalah, Jakarta: PT Raja Persada, 2013.

Kompilasi Hukum Ekonomi Syariah Bandung: Fokus Media, 2010.

Kamsir dan Jakfar, Studi Kelayakan Bisnis, Jakarta: Kencana Pranada Media Group, 2003.

Lexy J. Meleong, Metode Penelitian Kualitatif, Jakarta: Rineka Cipta, 2003.

Muhammad Nazir, Metode Penelitian, Jakarta: Ghalia Indonesia, 1998.

Sayyid Sabiq, Kamaluddin A. Marzuki , fiqih sunnah 12, Bandung: Al-ma'arif, 1998.

Suhaesimi Arikunto, Prosedur Prosedur Penelitian Suatu Pendekatan Praktek, (Jakarta: PT Rineka Cipta, 2002.

Tim Penyusun, Buku Panduan Penulisan Skripsi, (Fakultas Syariah dan Ilmu Hukum Institut Agama Islam Negeri Padang Sidimpuan, 2014. 
224 | TAZKIR: Jurnal Penelitian Ilmu-ilmu Sosial dan Keislaman Vol. 03 No. 2 Desember 2017

\section{Kedudukan DPD RI Dalam Sistem Tata Negara Perspektif Siyasah}

SITI NURKHADIJAH \& ZUL ANWAR AJIM HARAHAP IAIN Padangsidimpuan 